\title{
Repetir, Memorizar, Recitar: Mecanismos para a Fabricação de Corpos Dóceis pela Educação Matemática
}

\author{
Repeat, Memorize, Recite: Mechanisms for Producing Docile Bodies Through the \\ Mathematics Education
}

\author{
Alice Stephanie Tapia Sartori*a; Claudia Glavam Duarte ${ }^{\mathrm{a}}$
}

${ }^{a}$ Universidade Federal do Rio Grande do Sul. RS, Brasil.

*E-mail: alice.stephanie.ts@gmail.com

\begin{abstract}
Resumo
Este artigo tem como objetivo discutir e problematizar o ensino de matemática pautado nas práticas de memorização que, juntamente com a repetição e a recitação, mesmo que questionadas, ainda hoje, fazem parte desta disciplina escolar. O presente estudo parte das reflexões realizadas em uma Tese de Doutorado e tem como material empírico exemplares da Revista Nova Escola publicados entre os anos 1986 e 2015. A partir do referencial teórico e metodológico elaborado pelo filósofo Michel Foucault, buscamos dar visibilidade ao entrelaçamento de alguns enunciados que se configuram na análise das Revistas. Dentre os resultados da pesquisa, destacamos que: algumas práticas de memorização estavam, no passado, ligadas aos castigos físicos e, posteriormente, foram sendo reconfiguradas e adequadas às penalidades do espírito; o uso do corpo no ensino de matemática, para além das penalidades, estava ligado aos exercícios da mente, que incluem os treinos de memória ligados aos exercícios repetitivos; repetição constante estava alinhada ao ensino mecanizado desta disciplina; a recitação buscava transformar os mínimos gestos do corpo em força útil; e, por fim, a apreensão do tempo dos estudantes, visando ao seu máximo aproveitamento de forma linear e contínua, era um dos aspectos que perpassavam as práticas de memorização. Portanto, o estudo nos aponta para uma forma de poder, a qual Foucault denominou poder disciplinar, que atua na produção de corpos dóceis pela maquinaria escolar.
\end{abstract}

Palavras-chave: Memorização. Educação Matemática. Poder disciplinar.

\begin{abstract}
This paper aims to discuss and problematize the teaching of mathematics based on memorization practices, which together with repetition and recitation, even if questioned, are still part of this school discipline. This study, which parts of the reflections made in a Doctoral Thesis, has as empirical material Revista Nova Escola examples, published between 1986 and 2015. From the theoretical and methodological framework elaborated by the philosopher Michel Foucault, we seek to give visibility to the intertwining of some statements that are configured in the analysis of the Magazines. Among the research results, we highlight that: Some memorization practices were, in the past, linked to physical punishments, and were later reconfigured and appropriate to the penalties of the spirit; The use of the body in the teaching of mathematics, besides penalties, was linked to the exercises of the mind, which include memory training; this notion of body would be linked to repetitive math exercises; constant repetition would be in line with the mechanized teaching of this discipline; The recitation sought to transform the minimum gestures of the body into useful force; and, finally, the apprehension of the students'time, aiming at its maximum use in a linear and continuous way, is one of the aspects that pervade the memorization practices. Therefore, the study points us to a form of power, which Foucault called the disciplinary power that acts in the production of docile bodies by school machinery.
\end{abstract}

Keywords: Memorization. Mathematics education. Disciplinary Power.

\section{Introdução}

Este artigo tem como objetivo discutir e problematizar o ensino de matemática pautado nas práticas de memorização que, juntamente com a repetição e a recitação, mesmo questionadas, ainda fazem parte do ensino desta disciplina. O presente estudo parte das reflexões realizadas em uma Tese de Doutorado e tem como material empírico exemplares da Revista Nova Escola publicados entre os anos 1986 e 2015.

Mesmo que o discurso em torno das práticas de memorização tenha sido modificado ao longo dos anos, há pelo menos uma década, as Revistas analisadas ainda apontam indícios de um ensino baseado na memorização. $\mathrm{O}$ primeiro excerto abaixo mostra que a memorização perpassa a Educação Básica. Conforme uma das Revistas publicadas em 2008, que aponta dados percentuais de uma pesquisa sobre as escolas brasileiras, os métodos mecânicos de memorizar, copiar e recitar fórmulas ainda estavam em vigor e necessitavam ser problematizados. Podemos observar essa preocupação também em Revistas mais recentes, publicadas a partir do início deste século, o que evidencia que tais práticas não foram destituídas de importância, mas ainda fazem parte do cotidiano de muitas escolas:

Um estudo do Instituto de Estatística da Organização das Nações Unidas para a Educação, Ciência e a Cultura (Unesco), feito entre 2005 e 2007 em escolas primárias de 11 países da América Latina, da Ásia e da África, revela que o Brasil é um dos líderes na utilização de métodos mecânicos. [...] $63,8 \%$ das classes repetem sentenças. 64,2\% recitam 
tabelas e fórmulas (Revista Nova Escola, n. 214, 2008, p. 28). Depois de aplicar e analisar os resultados de um teste sobre as quatro operações elementares com números naturais, um grupo de professores do Instituto de matemática da Universidade Federal do Rio de Janeiro chegou à conclusão de que o ensino-aprendizagem de matemática no primeiro grau caracteriza-se por adestramento e memorização de técnicas para efetuar operações e resolver problemas (Revista Nova Escola, n. 33, 1989, p. 38).

A tabuada é a mesma do tempo em que você era aluno e, provavelmente, tinha de decorá-la. O conteúdo era tão valorizado que as listas de multiplicações apareciam estampadas nos lápis e na contracapa dos cadernos. Mesmo assim, na hora de usar esse conhecimento, muitas vezes os valores sumiam da memória, não é mesmo? Prova de que as práticas tão consolidadas de memorização pela repetição não são eficazes (Revista Nova Escola, n. 248, 2011, p. 37).

Além de estarem supostamente atreladas aos rastros do passado da Educação, como o legado dos jesuítas, por exemplo, as práticas de memorização neste contexto parecem estar estreitamente ligadas às mudanças sociais e econômicas que possibilitaram a emergência de novas relações de poder para além do campo educativo. Deste modo, podemos inferir que apesar das distintas denominações dos movimentos e tendências pedagógicas que atravessaram o ensino de matemática por volta do século XX, a memorização sempre teve seu lugar de destaque, mesmo sendo colocada em suspeição pelos discursos educacionais hegemônicos. As explicações para sua permanência são diversas e estão de acordo com as perspectivas teóricas e metodológicas de cada autor que, em seu campo de pesquisa, investigou a história do ensino desta disciplina.

Para este estudo, o referencial teórico e metodológico que nos permitiu tal problematização advém das teorizações do filósofo Michel Foucault e de seus comentadores. Essas reflexões nos possibilitaram pensar a escola como um espaço privilegiado para a constituição de sujeitos. Assim, a partir da perspectiva foucaultiana, nossa intenção neste artigo é investigar as práticas de memorização no ensino de matemática inscritas no interior das relações de poder que conformam subjetividades, dando visibilidade às continuidades e rupturas dos discursos presentes nas Revistas Nova Escola.

\section{O Material Empírico e as Ferramentas Teórico- Metodológicas}

Desde sua primeira edição, em 1986, a Nova Escola é uma das revistas de maior circulação e de ampla tiragem do Brasil, conforme afirma Aquino (2013). Nas palavras do autor, essa Revista "se revela, de um lado, como caixa de ressonância da mentalidade pedagógica dominante no país e, de outro, como laboratório de formatação discursiva dessa mesma mentalidade" (p. 206). Tem como público alvo, atualmente, professores da Educação Infantil, do Ensino Fundamental e do Ensino Médio, estudantes da área da Educação ou profissionais que atuam nesse campo. A Fundação Victor Civita, criada em 1985 pela Editora Abril, foi responsável pela Revista até 2015, quando a fundação transferiu a Nova

\section{Escola para a Associação Nova Escola.}

Para a proposta realizada na Tese, de modo geral, foram analisados 235 exemplares, publicados entre 1986 e 2015, e deles foram extraídas as enunciações que posteriormente formaram o corpus de análise da pesquisa. Especialmente para este artigo, destacamos enunciações de 26 destas Revistas que nos apontam para o objeto de estudo, as práticas de memorização associadas ao poder disciplinar, discussão a qual nos detemos ao longo deste artigo. Nesse sentido, consideramos as Revistas como superfície de inscrição de discursos de professores e pesquisadores no campo da Educação e da Educação Matemática sem, no entanto, fazer um juízo de valor sobre tais discursos.

Mas, de modo mais específico, como olhamos para este conjunto de elementos nas Revistas que nos conduzem ao objeto a ser estudado? Quais as lentes que nos permitem enxergar esses elementos e não outros? Segundo entendimento amplamente compartilhado e difundido por diversos autores e comentadores de Foucault, as teorizações elaboradas pelo filósofo nos fornecem ferramentas tanto teóricas quanto metodológicas advindas da análise do discurso, as quais procuramos explanar aqui de modo sucinto.

As proposições sobre a análise do discurso são constituídas por diversos conceitos, como o de enunciado, formação discursiva, história, dispositivo, sujeito, acontecimento, dentre outros, e a própria concepção de discurso, entendido como:

um conjunto de enunciados, na medida em que se apoiem na mesma formação discursiva; ele não forma uma unidade retórica ou formal, indefinidamente repetível e cujo aparecimento ou utilização poderíamos assinalar (e explicar, se for o caso) na história; é constituído de um número limitado de enunciados para os quais podemos definir um conjunto de condições de existência (Foucault, 2008, p.132).

Os enunciados são estabelecidos ainda a partir de enunciações. Uma enunciação se expressa sempre que um conjunto de signos é emitido, e é também um acontecimento, mas que não se repete, ao contrário do enunciado. Um enunciado pode ser composto por múltiplas enunciações. Como explicou Foucault (2008), quando uma pessoa diz algo, podemos tomar esta fala como uma enunciação. Se outra pessoa diz o mesmo e ao mesmo tempo, avaliamos que existem duas enunciações, o que expressa sua singularidade. De tal modo, para uma especulação histórica pode-se analisar enunciações que produzem enunciados naturalizados como verdades em diferentes épocas.

Os estudos realizados por Foucault nos permitem analisar discursos e problematizá-los, focalizando o modo como atuam em consonância com a constituição de sujeitos. Ou seja, frisar os discursos presentes nas Revistas é uma operação que permitirá romper com a validade do óbvio, deslegitimando o presente e transformando um fato que, a priori, seria natural, em algo problemático. Nossa tarefa seria então desconfiar dos fatos naturalizados sobre a memorização nesse âmbito, considerando que eles têm "uma emergência em 
um determinado momento histórico, para se dissolver, mudar de contornos, redefinir-se, passar por rupturas mais adiante" (Albuquerque Junior, 2007, p.150).

Fazer uso instrumental da história por meio dos discursos, nessa perspectiva, provoca um questionamento das práticas contemporâneas a partir de seus rastros no passado, ou seja, identifica quais relações históricas as articulam. Trata-se de trazer as práticas à superfície e de fazer insurgir aquelas que foram submersas por não apresentarem, a priori, autoridade para a constituição de uma história. Sendo assim, a intenção deste estudo não é abarcar uma totalidade histórica que abrangeria o espírito de uma época, mas levar em conta as consequências de um pensamento que engendrou transformações em diferentes âmbitos na sociedade, em especial, na Educação. Em outras palavras, esta pesquisa objetiva dar uma compreensão ao "modo de ser das coisas" (Foucault, 1999, p.XIX) que perpassa uma época, as alterações dos fluxos e algumas interrupções neste campo de saber.

Elegendo Foucault como nosso interlocutor teórico, pretendemos evidenciar nas Revistas as enunciações a respeito das práticas de memorização em diferentes épocas e dar atenção às subjetividades que estavam/estão sendo produzidas e disponibilizadas, uma vez que, nessa perspectiva, existe uma relação entre os discursos e a formação de subjetividades. Este trabalho analisa os enunciados que atravessam o campo da Educação Matemática entendendo-os a partir de um tempo, um lugar e uma positividade concreta por meio de práticas e instituições. Tal empreendimento se configura como um modo de interrogar singularidades marcantes da identidade do sujeito, atendendo à sua provisoriedade histórica e às formas de poder que o constitui.

Nesse sentido, ainda caberia uma reflexão sobre o que Foucault entende por poder. Suas análises mostraram que o poder não se encontra localizado unicamente no aparelho do Estado e que pode partir da periferia ao invés do centro: “é preciso ver como as grandes estratégias de poder se incrustam, encontram suas condições de exercício em microrrelações de poder" (Foucault, 1999, p. 249). Rompe, ainda, com a ideia do poder como algo repressivo ou negativo. Para o filósofo, o poder transforma o corpo, adestra e o aprimora, e por isso é entendido como superfície de inscrição. Assim, tais relações perpassam as diversas instituições, incluindo a escola, conforme discute o filósofo em sua conhecida obra Vigiar $e$ Punir (2011), evidenciando uma forma de poder específica: o poder disciplinar.

A tentativa de mostrar o corpo investido pelo poder disciplinar nos demanda uma atenção às mínimas operações que o compõe. Atentando aos detalhes das práticas em Educação Matemática, elencamos aquelas relacionadas à memorização, pois as consideramos como "técnicas sempre minuciosas, muitas vezes íntimas, mas que têm sua importância: porque definem um certo modo de investimento político e detalhado do corpo, uma nova "microfísica do poder" (Foucault, 2011, p.134). Assim, questionamos: como o corpo foi sendo sutilmente capturado por essas práticas de memorização na escola, especialmente nas aulas de matemática?

\section{Repetição, Memorização e Recitação: Vestígios do Poder Disciplinar}

O primeiro aspecto que gostaríamos de destacar para iniciar esta análise está relacionado aos castigos, já que quando se fala em memorização tem-se a ideia, fundamentada no senso comum, de que tais práticas no passado estariam ligadas aos castigos físicos quando as obrigações não eram cumpridas pelos estudantes. Nesse sentido, o estudo de Nürnberg (2008) aponta que os exercícios e as avaliações envolvendo a tabuada no ensino tradicional estavam relacionados aos castigos e às desobediências quando o professor exigia do aluno a tabuada do 1 ao 10 , escrita uma ou várias vezes no caderno, aliada à acometimentos físicos, como forma de punição:

era comum o aluno memorizar uma série de exercícios, e, após o sorteio feito pelo professor de um ou mais desses exercícios, ter que recitá-los ou escrevê-los. Para fazer prevalecer e salvaguardar sua autoridade, muitas vezes, o professor recorria à atitude policialesca, como: castigo (por exemplo, escrever mil vezes uma determinada tabuada) e agressões verbais e físicas (Damazio 2000, apud Nürnberg, 2008, p.31).

Exemplo conhecido de tais práticas punitivas é a palmatória, que de certa forma "bebe da mesma fonte" do ritual do suplício do final do século XVIII, pois admite a corporeidade da pena para castigar o erro, conforme analisa Foucault (2011). Os exercícios de matemática se configuravam como um importante instrumento para castigar os alunos por meio dessas "pedagogias". Não saber de cor a tabuada, por exemplo, submetia o aluno aos castigos físicos como exemplifica o seguinte excerto:

Eu sou do tempo em que a criança, por não saber direito a tabuada, ia para o quarto escuro, ficava de joelhos sobre o feijão ou de castigo no canto da sala (Revista Nova Escola, n. 12, 1987, p.17).

Nesse contexto escolar, a ideia do "saber decorado" também parece estar ligada à imagem de autoridade do docente, visto que o mestre tinha a função de executar os castigos naqueles que não se apropriavam do conteúdo solicitado. Essa tática fez parte de um conjunto de penalidades impostas aos educandos, de modo que o professor tomava nota dos exercícios associados também à matemática.

Gradativamente, os castigos foram desaparecendo das escolas. Porém, as punições ou penalidades também são manifestadas nessa instituição mediante as ações que controlam a utilização do corpo, do tempo, dos modos de expressão etc. Sobre aquele aluno que foge da norma, que se desvia do comportamento adequado às regras, atuam micropenalidades por meio da vigilância no espaço confinado da escola. Tais mecanismos de poder tomaram diferentes formas ao longo de sua permanência na sociedade, pois a ênfase na violência sobre o corpo foi sendo substituída pela ação do poder sobre alma do sujeito. Assim, essas novas formas de castigo mantêm 
seu foco na não corporeidade da pena, ou seja,

não mais se castiga direta e publicamente o corpo. Mas pode-se pensar, também, como a escola eliminando aos poucos a palmatória, faz a substituição por um conjunto de práticas em que a punição é exatamente a restrição ao movimento e à comunicação com os demais. Há, portanto, efeitos físicos. Mas, o objetivo imediato é a reeducação da alma do indivíduo (Guirado, 1996, p.63).

Qual a relação castigo-corpo imposta por este novo tipo de poder? Certamente ela difere daquela relação estabelecida pelos rituais do suplício. Como afirma Foucault (2011), o corpo castigado era alvo de sensações insuportáveis, enquanto que o corpo nessa outra perspectiva é objeto de uma economia dos direitos suspensos. Abolindo-se o espetáculo dos suplícios, se extingue o domínio sobre o corpo como objeto punitivo e este passa a ser apenas um instrumento para atingir a alma. Ao invés de causar dor no corpo, essas penalidades pretendem interferir na suposta liberdade do sujeito, privando-o de seus direitos sem sofrimento físico, caracterizando assim uma penalidade incorpórea.

$\mathrm{Na}$ oficina, na escola, no exército funciona como repressora toda uma micropenalidade do tempo (atrasos, ausências, interrupções das tarefas), da atividade (desatenção, negligência, falta de zelo), da maneira de ser (grosseria, desobediência), dos discursos (tagarelice, insolência), do corpo (atitudes "incorretas", gestos não conformes, sujeira), da sexualidade (imodéstia, indecência). Ao mesmo tempo é utilizada, a título de punição, toda uma série de processos subtis, que vão do castigo físico leve a privações ligeiras e a pequenas humilhações levando ao extremo, que tudo possa servir para punir a mínima coisa; que cada indivíduo se encontre preso numa universalidade punível-punidora (Foucault, 2011, p. 172).

A partir de procedimentos que envolvem a vigilância são impostas micropenalidades como punições que são mais eficazes do que o castigo corporal, tanto na escola como em outras instituições como a prisão. Se a função do corpo não era mais a de um objeto do suplício das penas, mas de uma superfície de inscrição do micro poder, à escola caberia não empregar mais os castigos físicos, mas uma série de exercícios "tediosos" e repetitivos, como os castigos pela escrita, que garantem a eficácia e economia dos corpos. Assim, podemos entender que castigar é exercitar. Citando o texto de La Salle, analisado por Foucault, observamos que

o castigo escrito é, de todas as penitências, a mais honesta para um mestre, a mais vantajosa e a que mais agrada aos pais; [permite] tirar dos próprios erros das crianças maneiras de avançar seus progressos corrigindo-lhes os defeitos; [àqueles, por exemplo], que não houverem escrito tudo o que deveriam escrever, ou não se aplicaram para fazê-lo bem, se poderá dar algum dever para escrever ou para decorar (La Salle apud Foucault, 2011, p. 17).

Como sinalizado pelo filósofo, o castigo escrito ocasionalmente vem acompanhado de exercícios para decorar ou de outras micropenalidades que reprimem e corrigem ao mesmo tempo por intermédio dos comandos do mestre. Vejamos nas Revistas analisadas, como o "decorar" nas aulas de matemática é entendido como castigo, que por vezes aparece entrelaçado a outras formas sutis de punição. Ademais, os excertos destacados apontam também para algumas espécies de castigos comum nas escolas "do passado" e alguns possíveis efeitos de sujeição aos corpos dos estudantes:

Normalmente eu os mando repetir vinte ou trinta vezes as lições que já foram corrigidas. Além de melhorar a caligrafia, este castigo serve também como uma reflexão para que se autodisciplinem (Revista Nova Escola, n. 11, 1987, p. 20-21). A garotada também fala: Um dos piores castigos na $3^{\mathrm{a}}$ série era decorar a tabuada. Por isso, bolei um método: para saber quanto é 7x8, uso a tabuada do 5 (Revista Nova Escola, $n$. 190, 2006, p. 18).

Com sua experiência, construída ao longo de mais de duas décadas como professor, Aguinaldo percebeu que a Matemática, da maneira como é dada na maioria das escolas, dificilmente vai conquistar alguém. Pelo contrário, vai é aborrecer muita criança, que se vê forçada a decorar um negócio que não entende direito e a faz suar frio quando chega a hora da prova (Revista Nova Escola, n. 65, 1993, p. 20).

Uma vez por semana, as aulas de Matemática da $5^{\mathrm{a}}$ série C do Colégio Estadual Adaile Maria Leite, em Maringá, a 423 quilômetros de Curitiba, são dominadas pelo silêncio. Mas isso não tem nada a ver com algum tipo de castigo. Ao contrário. A turma está concentrada em desenvolver estratégias para resolver, de cabeça, as contas propostas (Revista Nova Escola, n. 216, 2008, p.70).

Conforme mostram os excertos, os castigos impostos aos alunos que se caracterizam não mais como físicos, mas como castigos ao "espírito", agem de modo que o próprio aluno reconheça seu erro. Nas palavras de Foucault (2011, p. 173), essa forma de castigo objetivava reduzir os desvios, sendo, portanto, corretivo, pois "os sistemas disciplinares privilegiam as punições que são da ordem do exercícioaprendizado intensificado, multiplicado, muitas vezes repetido". Observando o relato de um professor em uma Revista de 1987, vemos que o castigo não é mais a melhor tática utilizada, mas sim o autoconvencimento do aluno de sua falha. Nesse contexto, ter que decorar conteúdos de matemática acaba se tornando também um castigo, já que provoca medo e aversão do estudante a essa disciplina. E, por fim, do último excerto, podemos supor que o silêncio absoluto poderia ser considerado como uma estratégia escolar disciplinar, ao contrário do que se espera hoje, em que silêncio é sinônimo de concentração nas aulas de matemática ${ }^{1}$.

A discussão iniciada por vias do castigo físico e continuada pelos castigos da alma foi realizada para dar visibilidade à forma como analisamos as práticas de memorização a partir do entendimento foucaultiano de relações de poder. Isto é, o poder não é somente punitivo, ele age sobre o corpo do aluno

1 A dissertação de Santos (2017) evidencia que o silêncio aliado à repetição, à organização e à concentração são condições necessárias para aprender matemática, conforme análise que realizou em um Colégio Militar, em uma turma de Ensino Médio. O autor observou uma articulação entre a disciplina-corpo e a disciplina-saber, em que a matemática se destaca em sua função disciplinar nesse espaço militarizado. 
através da autoridade do professor. Na medida em que pretende modificar comportamentos e endireitar o espírito do estudante, o poder é também positivo. Nesse sentido, Foucault denomina tais conformações de poder disciplinar e mostra como, nas mais diferentes instituições de sequestro, esse poder foi se consolidando na sociedade. Assim, investigaremos elementos sobre a memorização que perpassam as Revistas focando na análise das condições e especificidades do poder que atuam e produzem corpos dóceis na escola.

Em diferentes épocas, o uso do corpo na aprendizagem da matemática escolar passou por deslocamentos a fim de adequar-se aos discursos pedagógicos próprios de cada período histórico. Considerando as especificidades de cada regime discursivo, podemos entender que os corpos das crianças são investidos de técnicas que acabam por atingir suas almas, os moldando para um determinado fim. Por exemplo, "na pedagogia tradicional, o corpo da criança precisava ser silenciado, contido, passivo, na pedagogia proposta pela Escola Nova passa a ser investido desde outra lógica de disciplinamento, ou seja, desde um novo modus operandi: um corpo que "baila" (Taschetto \& Duarte, 2014, p.148).

Taschetto e Duarte (2014) identificaram uma nova forma de investir sobre o corpo infantil no momento em que o ensino de matemática passava por uma transição da Escola Tradicional para a Escola Nova. A partir do material coletado em exemplares da Revista do Ensino/RS publicadas entre 1939 e 1941, os autores concluem que o corpo infantil passou de uma posição silenciada, contida, passiva, atributos da pedagogia tradicional, para um corpo investido desde outra lógica de disciplinamento, por meio de técnicas mais dinâmicas, participativas, a fim de requisitá-lo ativamente no processo de ensino e de aprendizagem da matemática escolar. Para atender a esse novo modo de funcionamento, as práticas para o ensino da Matemática vinculadas ao ensino tradicional, tais como repetir, decorar, memorizar, foram reativadas e reconfiguradas, adequando-se, neste caso, às propostas de uma pedagogia progressista.

Para compreender tais reconfigurações relacionadas à memorização, é interessante examinar as práticas de sujeição da alma impostas a crianças por meio do emprego de exercícios corporais específicos. As práticas de repetição e memorização não foram abandonadas. Apesar das inaugurações dos novos ideais pela Escola Nova, elas ainda eram bem-vindas no ensino da matemática escolar. Entretanto, o uso pedagógico de forma mecanizada dos conteúdos não podia mais se constituir em uma "mecanização meramente decorada". Para que os educandos não se tornassem "simples papagaios", um corpo emudecido e contido, eles deveriam deixar de ser passivos no processo de aprendizagem e tornarem-se participativos. Uma das táticas evidenciadas para essa nova proposta é aquela que coloca em prática a participação do corpo inteiro do aluno na atividade do espírito, ou seja, em recitações ritmadas em que o corpo acompanhava a voz da criança. Os movimentos corporais cadenciados eram essenciais para o treino da memorização: o corpo que dança, bate palmas e tamborim, se movimenta e é capturado pela sedução do ritmo cadenciado executado coletivamente (Taschetto \& Duarte, 2014).

O poder investido no exercício repetitivo, na mecânica instituída, marcada pelo uso instrumental do corpo, pretende mais do que atingir o corpo propriamente dito: pretende atingir a alma, "trabalha[r], modifica[r], dirig[ir] o que Servan chamava de 'fibras moles do cérebro'." (Foucault, 2006, apud Taschetto \& Duarte, 2014, p. 152). Assim, observamos que o exercício da mente atravessa o exercício do corpo de modo geral, estando conectados pelas práticas pedagógicas. Neste ponto, vale fazermos alusão à teoria da psicologia das faculdades que atribui à mente, incluindo a memória, exercícios semelhantes aos dos músculos, o que conferiu visibilidade ao uso do corpo no ensino de aritmética no passado:

Outro importante fator que influenciou as aritméticas escolares é o reconhecimento da teoria da psicologia das "faculdades" que considera que a mente está constituída por diversas faculdades como imaginação, memória, percepção e raciocínio; que estas faculdades são, grosso modo, análogas aos músculos e que como tais devem ser exercitados por meio de treinamentos. Neste marco de pensamento explicase a "disciplina mental" como um objetivo educativo que se consegue por meio de um esforçado trabalho intelectual em torno daquelas disciplinas que se consideravam mais adequada para o treinamento da mente. Os cálculos aritméticos eram vistos como bons exercícios para fortalecer e amadurecer a mente. A grande quantidade de exercícios mentais de cálculo, aqueles que os alunos devem fazer sem o recurso de lápis e papel, tornaram-se exaustivos e marcaram aquela época (Costa, 2010, p. 102).

Nesse sentido, porém, sob outro ponto de vista, Masschelein \& Simons $(2017$, p) consideram que os procedimentos ou tecnologias de memorização podem desempenhar um aspecto formativo quando comparados com o exercício do corpo, pois tais práticas estimulam a atividade mental. Elas atuam como

uma espécie de ginástica escolástica. Os seres humanos praticam e estudam por meio dessas tecnologias - as quais têm uma longa história e um lugar proeminente na antiguidade grega. Elas são técnicas básicas para a pessoa experiente e culta que se esforça para alcançar e manter certo nível de vigor mental, do mesmo modo como as técnicas na educação física aprimoram o corpo em movimento (Masschelein \& Simons p. 61).

Nesse contexto, a partir de um olhar foucaultiano, é possível identificar diversos mecanismos disciplinares que atuam na sujeição desses corpos. Na questão do ritmo no aprendizado, por exemplo, Foucault (2011), ao se referir à articulação corpo-objeto, analisa as manobras cadenciadas executadas nos quartéis, afirmando que o ritmo imposto nesse espaço por meio de normas temporais objetivava destacar a rapidez e o acelerado processo de aprendizagem por meio do corpo.

Recordamos que, para Foucault, o modelo da fábrica traduz bem esse aspecto do corpo disciplinado, e a escola reproduziu e ainda reproduz regime semelhante alinhando os corpos aos 
aparelhos disciplinares. Especialmente na educação brasileira, alguns efeitos do modo de produção do capitalismo ressoaram nas práticas pedagógicas, em que a tendência tecnicista, conforme denomina Fiorentini (1995), adquiriu visibilidade no "regime fordista disciplinar". Nesse contexto, a finalidade do ensino de Matemática era capacitar o aluno para resolver exercícios e problemas, memorizar fórmulas e desenvolver atitudes computacionais. Com a tendência tecnicista em vigor, não era interesse da escola formar indivíduos críticos ou criativos, mas que tivessem determinadas funcionalidades na sociedade (Fiorentini, 1995).

Por esse ângulo, ficaria a cargo da escola mobilizar atividades que preparariam o aluno, futuro trabalhador, para o trabalho mecanizado, principalmente, de modo que a lógica disciplinar do exercício repetitivo recairia sobre as práticas pedagógicas. Nas aulas de matemática, os exercícios recorrentes tornavam-se cansativos para o aluno. A aprendizagem era assegurada por esta mecânica do corpo que exigia um treinamento contínuo. Ao reproduzir diversas vezes as mesmas "continhas", o ensino que esteve, por décadas, baseado na repetição, é criticado pelos professores nas Revistas. Nos exercícios feitos em classe, nas lições de casa e até nos livros didáticos, a repetição se apresenta até mesmo como uma espécie de penalidade que se utiliza do corpo e do espírito do aluno.

Aulas em que se expõem conceitos, fórmulas e regras e depois é exigida a repetição de exercícios, tão usadas até hoje, têm origem no começo do século 20. Porém sabe-se que elas não são a melhor opção para a Educação Matemática (Revista Nova Escola, n. 216, 2008, p. 64-65).

Quadros-negros repletos de exercícios de fixação têm grandes chances de causar arrepios nos alunos. Colocadas dessa forma, as contas se tornam repetitivas e cansativas (Revista Nova Escola, n. 123, 1999, p. 18).

[a escola] privilegia a linguagem simbólica e formal da Matemática que, além de complexa, está muito distante do que as crianças veem, ouvem e falam no cotidiano. Como só isso é repetido e levado em conta, o aluno vai perdendo a iniciativa e deixa de pensar por si mesmo (Revista Nova Escola, n. 81, 1994, p. 20).

Quem não gostava de Matemática, como Clara Guzzella, 9 anos, acabou mudando de opinião. Novata na escola e acostumada a um ensino tradicional, "chato e cheio de exercícios repetidos", como diz, ela a princípio se surpreendeu com a ideia de trabalhar com textos (Revista Nova Escola, n. 83, 1995, p. 23).

elas [as crianças] rejeitam a atitude acrítica e a repetição não criativa que se exige delas. Reivindicam o espaço da vontade, do desejo, da criação (Revista Nova Escola, n. 43, 1990, p. 27).

em vez de dirigir a turma em exercícios rígidos e cansativos, por que não aproveitar as aulas de Educação Física para brincar? só assim você estará ajudando seus alunos a crescer de verdade (Revista Nova Escola, n. 6, 1986, p. 19).

O ensino pela repetição consistiria na exposição de regras e fórmulas pelo professor e, em sequência, de vários exercícios semelhantes, a tal ponto de se tornarem tediosos para os estudantes, como afirmam as reportagens. Desse modo, segundo as reportagens, a matemática ensinada não serviria para o aluno, já que ele, apenas por repetir o que o professor propõe, não apreenderia os conceitos, fórmulas e regras, apenas os memorizaria. Portanto, os exercícios repetitivos inibiriam a criatividade e a criação, já que se baseiam apenas em copiar, imitar, e reproduzir aquilo que o professor afirmava como saber inquestionável. O último excerto ainda sugere que o corpo pode ser exercitado não pela repetição, que esgotaria mentalmente o aluno, mas pelo corpo movimentado, aliando a matemática a outras disciplinas como a educação física.

Ainda em relação aos exercícios que envolvem o corpo disciplinado, podemos mencionar a recitação daquilo que o aluno, por repetir diversas vezes, acaba memorizando. Para demonstrar que o aprendizado foi efetivo, ou que simplesmente o aluno tinha "na ponta da língua" aquele conteúdo, o professor exigia que ele demonstrasse em voz alta perante a turma. Guardadas as especificidades, esses momentos lembram aqueles ensaiados pelos jesuítas, que reservavam o sábado e colocavam dispostos seus estudantes para recitarem aquilo que aprenderam durante a semana. As enunciações abaixo descrevem como essa cobrança era realizada com a intenção de assegurar a autoridade docente, conforme afirmam os autores:

O princípio é o mesmo tempo básico e desprezível: empurrar conceitos que devem ser relembrados e recitados pelos alunos toda a vez que o professor desejar. É mais ou menos um processo adotado com os papagaios ensinados (Revista Nova Escola, n. 134, 2000, p.12).

Memorizar resultados nas aulas de Matemática pode não ser a melhor recordação da escola. Para muita gente, o que vem à mente são os calafrios da temida hora em que a professora tomava a tabuada, o que exigia insistência e esforço para decorar os cálculos cobrados na chamada oral. É verdade que este tipo de decoreba está longe de ser a maneira mais adequada de ajudar a turma a avançar nos cálculos (Revista Nova Escola, n. 225, 2009, p.92).

Há algum tempo, saber a tabuada na ponta da língua era questão de honra para os estudantes, que eram cobrados por pais e professores. Mas, na hora de mostrar os "conhecimentos", era preciso que as questões fossem feitas na sequência: $5 \times 6$ ? $5 \times 7$ ? $5 \times 8$ ? Do contrário, muito se atrapalham na resposta. Nada mais natural. Afinal, essa era uma decoreba, no sentido definido no dicionário Houaiss: "Decorar fatos, geralmente para prestar exames escolares, sem a predisposição de entendê-los ou relacioná-los" (Revista Nova Escola, n. 209, 2008, p.59).

As duas irmãs abominam o processo de repetir as multiplicações em voz alta, até saber tudo na ponta da língua. "A memorização mecânica, sem um objetivo definido, pode levar a resultados absurdos", adverte Marina. "Um aluno pode falar que seis vezes seis é vinte e não perceber o erro" (Revista Nova Escola, n. 90, 1995, p. 20).

Defendo que o fundamental é entrar na cultura matemática, ou seja, a linguagem e o jeito de fazer a disciplina. Isso deve ser feito à moda dos matemáticos, que utilizam essa ciência para expressar uma forma de pensar - e não apenas uma recitação, como ocorre na escola, por meio da repetição de conteúdos que os alunos não entendem (Revista Nova Escola, n. 228, 2009, p. 30).

As situações didáticas em que o aluno deve resolver uma 
série de exercícios repetidamente, geralmente com a instrução "siga o modelo", é um típico exemplo do ensino mecanicista. Assim, a grande crítica feita pelos professores e pesquisadores em Educação Matemática nas Revistas analisadas refere-se à mecanização nos processos de ensino e de aprendizagem. Uma série de técnicas são incorporadas na sala de aula com o objetivo de mecanizar os corpos dos alunos para que assimilem os conteúdos matemáticos. Se a intenção era, em meados do século $\mathrm{XX}$, produzir um sujeito que se adequasse ao sistema das fábricas, aí estão alguns dos mecanismos mais sutis para o treinamento dos corpos na escola: o ensino mecanizado da matemática.

Sinalizando tais aspectos, observamos algumas semelhanças do modelo fabril com o ensino tecnicista que prevaleceu durante décadas nas escolas brasileiras. Vejamos quais as características e críticas apontadas pelas reportagens a esse modelo de instrução que acabou sendo fundamento para as práticas de memorização no ensino de matemática:

Não desejava trabalhar com alunos da $2^{\mathrm{a}}$ série que já tivessem sido transformados em máquinas de pensar, como resultado de uma instrução tradicional, crianças que podiam apenas contar, arquivar na memória, rememorar e, mecanicamente, seguir regras chamadas algoritmos (Revista Nova Escola, n. 70, 1993, p. 47).

"Raciocinar é uma coisa, repetir cálculos mecânicos é outra, e bem chata", conta o professor Marcelo Lellis, autor de livros didáticos. [...] Os exercícios exigem bastante raciocínio lógico e deixam a parte sempre aborrecida de contas para as calculadoras (Revista Nova Escola, n. 103, 1997, p. 33).

NE: Quais são os vícios no ensino de Matemática? Kátia: A resolução de exercícios repetitivos e mecânicos, a pouca exploração do erro como fonte de aprendizagem e o uso de problemas com respostas únicas, por vezes sem nenhum significado, são alguns dos equívocos e vícios que ainda contribuem para o insucesso (Revista Nova Escola, n. 155, 2002, p. 41).

"Saber Matemática é muito mais do que saber fazer conta no papel, de forma mecânica", diz Bigode. (Revista Nova Escola, n. 173, 2004, p. 40).

$\mathrm{O}$ ensino de matemática mecanizado, segundo as reportagens, transformava o aluno em uma espécie de "máquina de pensar". Porém, há outros professores que discordam que a mecanização auxilie no raciocínio lógico e defendem que, ao contrário, ela se opõe ao pensar e ao aprendizado significativo. Esses métodos seriam, portanto, "vícios no ensino de matemática", pois o aluno apenas "arquiva na memória" o conteúdo, mas não é possível verificar se realmente aprendeu, afirmam as reportagens. A repetição mecânica que utiliza quase toda a aula para o exercício das "continhas", além de aborrecer o aluno, o levaria a não enxergar os próprios erros.

Percebemos de forma sutil que o que estava em jogo nessas estratégias de memorizar, repetir e recitar era um controle minucioso do tempo de modo que não se precipitava a conclusão de tais processos, exigia-se do aluno uma atividade monótona até o momento de verbalizar aquilo de que havia se apropriado nas aulas. Algumas reportagens ainda indicam que nesse contexto se disponibilizava bastante tempo para a resolução de operações repetitivas e mecânicas, e que esse seria um dos erros que os professores cometem nas aulas de matemática. $\mathrm{O}$ maior tempo destinado às aulas muitas vezes se resumiam à resolução de "listas intermináveis" de contas equivalentes em métodos de resolução:

Se você conhece esse fracasso, não se culpe - nem responsabilize o estudante. "O equívoco é do modelo, não das pessoas”, afirma o professor Luiz Márcio Imenes, engenheiro civil, mestre em Educação Matemática e autor de livros didáticos. Segundo ele, os erros são históricos. O principal deles: gastar $95 \%$ do tempo das aulas fazendo continhas (Revista Nova Escola, n. 150, 2002, p.18).

A repetição exagerada de exercícios não ajuda a desenvolver o cálculo mental. Por isso, evite cobrar dos alunos listas intermináveis de contas (Revista Nova Escola, n. 116, 1998, p.25).

Não há nada mais chato e desestimulante que a repetição excessiva. Às vezes, porém, nos esquecemos disso e cansamos nossos alunos com listas de contas e mais contas sempre muito parecidas (Revista Nova Escola, n. 102, 1997, p.21).

Essa característica temporal também pode ser analisada por vias do poder disciplinar, já que a disciplina tenta extrair o máximo de tempo disponível e cada instante é transformado em força útil. Ela realiza uma capitalização do tempo. Além disso, as instituições de sequestro têm a função de fazer um mapeamento rigoroso dos corpos, pois não basta simplesmente ter o domínio sobre o tempo dos indivíduos, mas obter uma eficiência sobre ele a partir da composição das forças. O que é estimado é o tempo que cada indivíduo possui, que passa a ser oferecido ao aparelho de produção,] é preciso que o tempo dos homens seja colocado no mercado e seja transformado em tempo de trabalho (Foucault, 2013, p.115). A disciplina capitaliza o tempo, gerindo e tornando-o mais útil: "No bom emprego do corpo, que permite um bom emprego do tempo, nada deve ficar ocioso ou inútil: tudo deve ser chamado a formar o suporte do ato requerido" (Foucault, 2011, p. 147). O filósofo descreve também a escola como intensificadora dessa utilização do tempo, pois cada instante é imerso em atividades múltiplas e ordenadas, o ritmo dos sinais, apitos, ordens do mestre e comandos se tornam normas temporais que objetivam "acelerar o processo de aprendizagem e ensinar a rapidez como uma virtude" (Foucault, 2011, p.149). Na escola, as crianças deveriam executar rapidamente operações repetitivas por meio do quadriculamento do tempo, evitando "desperdícios" com outras ações sem importância.

Em síntese, podemos considerar o tempo destinado às atividades escolares, que exercitavam a memória, como um aspecto disciplinar que, em conjunto com outras táticas sutis, capturou o sujeito e o enquadrou em um padrão de docilidade. O corpo submetido a exercícios mecânicos de memória por meio da repetição e recitação foi forjado pela maquinaria escolar, tornando-o dócil em uma sociedade sustentada pela disciplina.

Portanto, partindo do pressuposto de que uma das exigências da modalidade disciplinar é "construir uma máquina cujo efeito será elevado ao máximo pela articulação 
combinada das peças elementares de que ela se compõe" (Foucault, 2011, p.158), compreendemos que as práticas de decorar, repetir, recitar no ensino de matemática constituemse como parte de uma engrenagem que constituem as forças desse aparelho eficiente.

\section{Considerações Finais}

Nas enunciações analisadas, observamos que os professores e especialistas com voz nas Revistas nos dão indícios de como o ensino de matemática funcionou em décadas anteriores, o que nos conduziu a uma análise das práticas de memorização aliadas à sociedade disciplinar. Podemos nos referir especificamente ao ensino da matemática, quando observamos a ênfase na memorização e no fato de que o professor deve estar atento à voz de cada aluno, que submetido ao exame, deve mostrar constantemente esse saber "na ponta da língua". Esse aspecto exemplifica como uma sanção normalizadora age sobre os corpos dos estudantes, buscando enquadrá-los, em suas individualidades, na norma que exige o saber de cor.

Os ritmos e prazos para o ensino e o uso do corpo como forma de garantir um aprendizado eficaz da matemática, alinhados ao confinamento e à distribuição espaço-temporal na escola, contribuem para formar um corpo exercitado. Desse modo, os procedimentos de ensino dos conteúdos matemáticos mostram indicativos de práticas que se assemelham a outras práticas vizinhas, que não são da ordem escolar, mas que contribuem para fabricar corpos dóceis em um sistema de pensamento sustentado por esse tipo de poder.

Portanto, neste artigo, buscamos dar visibilidade ao entrelaçamento de alguns enunciados que se configuram na análise das Revistas. Em síntese, constatamos que: 1) Algumas práticas de memorização estavam, no passado, ligadas aos castigos físicos, e posteriormente foram sendo reconfiguradas e adequadas às penalidades do espírito. 2) $\mathrm{O}$ uso do corpo no ensino de matemática, para além das penalidades, estava ligado aos exercícios da mente, que incluem os treinos de memória. 3) Essa noção de corpo estaria vinculada aos exercícios repetitivos de matemática os quais relacionamos à repetição demandada pelo aparato disciplinar. A repetição constante estaria alinhada ao ensino mecanizado da matemática em que o aluno era visto como uma máquina de pensar, seguindo modelos prontos e memorizando resultados, fórmulas e conceitos. 4) Destacamos ainda a recitação nas aulas de matemática que, aliada aos aspectos da mecanização e da repetição, buscava transformar os mínimos gestos do corpo em força útil. 5) Por fim, a apreensão do tempo dos estudantes, visando seu máximo aproveitamento de forma linear e contínua, é um dos aspectos que perpassam as práticas de memorização quando entrelaçado aos aspectos anteriores elencados.

Sendo assim, ponderamos que as práticas de memorização no ensino de matemática identificadas nas Revistas se deram por meio da repetição, mecanização e recitação, e, com efeito, contribuíram, mesmo que de forma ínfima, para a constituição de corpos dóceis pela maquinaria escolar. Por outro lado, observamos que esses métodos são explicitamente contestados desde as primeiras publicações da Nova Escola, já que iriam contra o pensamento autônomo e crítico dos estudantes. Em alguns casos, como na citação abaixo, as opiniões remetem às novas exigências da formação de cidadãos necessárias ao país:

O Mundo Mudou, nossas necessidades são outras. Hoje, depois de um longo período de ditadura, a sociedade brasileira ensaia a democracia. Nela, os dóceis alunos pouco pensantes e pouco críticos parecem não mais ter utilidade. [...] Antigamente, a disciplina se impunha como um instrumento de controle do professor sobre os alunos e substituía pela opressão e repressão qualquer outra pedagogia (Revista Nova Escola, n. 45, 1990, p. 18-19).

As mudanças pelas quais o Brasil passou, especialmente com o fim da ditadura na década de 1980, impulsionaram novos modos de subjetivação, como sugerem as Revistas. Que sujeitos são necessários a esta nova sociedade que ensaia a democracia? Para concluir, lançamos ainda outros questionamentos: como a memorização mecânica e a repetição no ensino de matemática foram se reconfigurando ou cedendo lugar a outras estratégias de ensino?

\section{Referências}

Albuquerque Junior, D.M. (2007). Um leque que respira: a questão do objeto em história. In: Albuquerque Junior, D.M. História: a arte de inventar. Bauru: Edusc.

Aquino, J. G. (2013). Pedagogização do pedagógico: sobre o jogo do expert no governamento docente. Educação, 36(2).

Costa, D. (2010). A aritmética escolar no ensino primário brasileiro: 1890-1946. Tese de doutorado. Programa de Estudos Pós-Graduados em Educação Matemática, Universidade Católica de São Paulo, São Paulo, SP, Brasil.

Fiorentini, D. (1995). Alguns modos de ver e conceber o ensino da Matemática no Brasil. Revista Zetetikê, 3(4).

Foucault, M. (2008). A arqueologia do saber. Rio de Janeiro: Forense Universitária.

Foucault, M. (2013). A verdade e as formas jurídicas. Rio de Janeiro: Nau.

Foucault, M. (1999). As palavras e as coisas: uma arqueologia das ciências humanas. São Paulo, Martins Fontes.

Foucault, M. (2011). Vigiar e Punir: nascimento da prisão. Petrópolis: Vozes.

Guirado, M. (1996). Poder indisciplina: os surpreendentes rumos da relação de poder. In: Aquino, J.G. Indisciplina na escola: alternativas teóricas e práticas. São Paulo: Summus.

Masschelein, J. \& Simons, M. (2017). Em defesa da escola: uma questão pública. Autêntica.

Nürnberg, J. (2008). Tabuada: significados e sentidos produzidos pelos professores das Séries Iniciais do Ensino Fundamental. Dissertação de Mestrado, Universidade do Extremo Sul Catarinense, Criciúma, SC, Brasil.

Santos, A.A.L. (2017). Repetição, silêncio, concentração, organização: articulações entre a Disciplina-Corpo e a Disciplina Saber (Matemática) no Colégio Feliciano Nunes Pires. Dissertação de Mestrado, Universidade Federal de 